Dea Letriana Cesaria: Religiositas Masyarakat Tionghoa dalam Cerpen di Majalah Star...

\title{
RELIGIOSITAS MASYARAKAT TIONGHOA DALAM CERPEN DI MAJALAH STAR WEEKLY, LIBERAL, DAN PANTJAWARNA TAHUN 1954-1956
}

\author{
The Religiosity of The Chinese Communities in The Short Stories \\ in The Star Weekly, Liberal, and Pantjawarna Magazine in 1954-1956 \\ Dea Letriana Cesaria \\ Badan Pengembangan dan Pembinaan Bahasa \\ Jalan Daksinapati Barat IV, Rawamangun, Jakarta, Indonesia \\ Pos-el: letrianadea@gmail.com
}

Naskah masuk: 21 Mei 2020, disetujui: 21 Juni 2020, revisi akhir: 27 Juni 2020

\begin{abstract}
Abstrak
Sastra Peranakan Tionghoa adalah karya sastra dalam bahasa Indonesia yang dihasilkan oleh orang Tionghoa yang dilahirkan di Indonesia. Seusai Perang Dunia II, sastra peranakan tetap berkembang. Bentuknya bukan lagi novel tetapi cerpen. Namun, berbeda dengan keadaan sebelum Perang Dunia II, pada zaman Pasca-Perang itu tidak lagi terdapat majalah seperti Tjerita Romans atau Penghidoepan. Kebanyakan karya dimuat dalam majalah-majalah umum atau berita, seperti Star Weekly, Liberal, dan Pantjawarna. Tujuan dari penelitian ini adalah melihat kontribusi majalah Star Weekly, Pantjawarna, dan Liberalpada tahun 1950-an terhadap publikasi karya penulis Tionghoa. Metode yang digunakan adalah metode kualitatif dan deskriptif. Hasil penelitian menunjukkan bahwa cerpen dalam majalah Star Weekly, Liberal, dan Pantjawarna menggambarkan religiositas masyarakat Tionghoa dalam menjalani kehidupan yang multikultural di Indonesia. Konsep kemanusiaan dalam ajaran Konghucu erat kaitannya dengan konsep Tepa Sarira dalam kebudayaan Jawa.
\end{abstract}

Kata kunci: religiositas, cerpen, majalah Tionghoa

\begin{abstract}
Chinese Literature is literary works in Indonesian produced by Chinese people who were born in Indonesia. After World War II, peranakan literature continued to flourish. The form is no longer a novel but a short story. However, in contrast to the situation before World War II, the Post-War era there were no magazines anymore, such as Tjerita Romans or Penghidoepan. Most of his work is published in public magazines or news, such as Star Weekly, Liberal, and Pantja Warna. The purpose of this study is to look at the contributions of Star Weekly, Pantja Warna and Liberal magazines in the 1950s to the publication of works by Chinese writers. The method used is qualitative and descriptive methods. The results showed that short stories in Star Weekly, Liberal, and Pantjawarna, magazines illustrate the religiosity of the Chinese community in leading a multicultural life in Indonesia. The concept of humanity in Confucianism is closely related to the concept of Tepa Sarira in Javanese culture.
\end{abstract}

Keywords: religiosity, short story, Chinese magazine

\section{Pendahuluan}

Periode Tahun 1950-an merupakan tahuntahun terjadinya krisis pada perkembangan dunia kesusastraan di Indonesia. Pada kurun itu, sastra Indonesia dipengaruhi oleh situasi sosial, politik, dan ekonomi. Keadaan sosial yang mengguncang melahirkan masalah di masyarakat, tidak adanya pemerataan dalam tingkatan sosial, serta krisis akhlak dan moral, sedangkan bidang ekonomi yang merosot menyebabkan kemiskinan, pengangguran, dan terhambatnya kemajuan di segala bidang. Situasi ini berakibat pada karya sastra yang lahir pada saat itu, yakni karya yang pada umumnya diterbitkan dalam majalah, termasuk karya sastra bergenre cerpen. Majalah-majalah yang memuat cerpen pada masa 1950-1959 itu antara lain Star Weekly, Liberal, Pantjawarna, Damai, 
Dea Letriana Cesaria: Religiositas Masyarakat Tionghoa dalam Cerpen di Majalah Star...

Roman, Indonesia, Warna, Aneka, Siasat, Cerita, Pemuda, Seni, Semi, Hikmah, dan sebagainya. Di antara banyaknya penerbitan cerpen dalam majalah tersebut terdapat karya-karya cerpen yang ditulis oleh penulis Tionghoa Peranakan. Mereka bahkan memiliki majalahnya sendiri misalnya Star Weekly, Liberal, dan Pantjawarna.

Mengapa ketiga majalah tersebut digolongkan sebagai majalah Tionghoa Peranakan? Pertama, majalah-majalah tersebut dimiliki oleh orang-orang Tionghoa Peranakan; kedua, majalah-majalah tersebut dipimpin dan dieditori oleh orangorang Tionghoa Peranakan; ketiga, pengisi majalahnya juga orang-orang Tionghoa peranakan. Terkadang, beberapa orang penulis Indonesia juga mengisi ruang dalam majalah-majalah tersebut. Satu di antaranya adalah Pramoedya Ananta Toer. Hal yang juga menjadi ciri khas majalahmajalah ini bahwa di setiap bulan Februari ketiga majalah ini menerbitkan edisi khusus perayaan tahun baru Tionghoa, Sintjia. Sementara itu, Suryadinata (1996) menyatakan bahwa sesudah Perang Dunia II karya-karya penulis Tionghoa Peranakan bukan lagi berbentuk karya roman tetapi karya cerpen yang banyak dimuat di majalah-majalah Star Weekly, Liberal, dan Pantjawarna (hlm. 20). Majalah-majalah itu memuat cerpen yang pada umumnya menyuguhkan tema berbau politik, ekonomi, sosial, revolusi, dan sedikit sekali yang mengangkat religiositas.

Sebagai akibat dari pergaulan dan interaksi sosial yang cukup lama antara masyarakat Cina dengan kelompok etnis lain, baik pribumi maupun etnis dari luar Indonesia, dewasa ini masyarakat Cina di kawasan Pecinan sudah banyak yang menjadi pemeluk agama-agama yang diakui negara seperti Budha, Islam, Kristen /Protestan dan Katolik. Orang-orang Cina yang ada di Indonesia pada umumnya melaksanakan ritual-ritual yang berkaitan dengan pemujaan Budha, Tao dan Konfusius. Dalam perkumpulan Tri Dharma atau Tiga Agama yang disebut Sam Kauw Hwee, orang-orang Cina memuja sekaligus tiga agama ini. Sebenarnya Konfusianisme dan Taoisme merupakan ajaran-ajaran falsafah agar manusia hidup secara baik dan harmonis, tetapi oleh orang-orang Cina di
Indonesia ajaran-ajaran falsafah ini sudah dianggap sebagai agama. (Hartono, 1974: 66).

Inti dari Taoisme adalah keharmonisan hubungan antara manusia dengan Tuhan, manusia dengan alam, manusia dengan dewa-dewi, anak dengan orang tua, sesama saudara, suami dengan istri, pemimpin dengan rakyat, sesama teman dan sesama anggota masyarakat lainnya. Hubungan yang harmonis ini harus dilandasi oleh rasa cinta dan kasih, keadilan dan kebijaksanaan, kesusilaan dan sopan santun, kecerdasan dan kewaspadaan, kejujuran dan keiklasan (Hidayat, 1993: 17). Oleh karena itu, penghormatan dan pemujaan kepada Tuhan, dewa-dewi dan leluhur selalu dilakukan melalui upacaraupacara yang dilakukan di kelenteng maupun di rumah.

Falsafah Konfusianisme lebih menekankan pada etika kehidupan yang bersifat duniawi. Hal ini dapat kita simak pada ucapan Konfusius yaitu bagaimana manusia dapat mengetahui hal-hal yang berhubungan dengan kematian, jika hal-hal yang berhubungan dengan kehidupan belum mereka ketahui (Koentjaraningrat, 2002: 367). Ajaran Konfusianisme merupakan cara pembelajaran menjadi manusia melalui interaksi dengan sesama manusia secara terus-menerus. Pembelajaran menjadi manusia ini mengandung empat dimensi pemahaman. Yang pertama, berkaitan dengan cara menyatukan dan menyelaraskan antara hati dan pikiran dengan tubuh dan jiwa. Kedua, cara menjalin hubungan yang bermanfaat dengan komunitas manusia secara luas, baik dengan keluarga, masyarakat, bangsa dan komunitas global. Ketiga, cara menjalin hubungan yang harmonis, bermanfaat dan berkelanjutan dengan alam. Keempat, cara menyelaraskan hubungan antara jiwa dan pikiran dengan Tuhan penguasa semesta (Tu Wei-Ming, 2005: 14)

Intisari dari Konfusianisme terletak pada masalah keluarga dan ketatanegaraan. Keharmonisan keluarga dikaitkan dengan bentuk kebaktian kepada orang tua, yang kemudian diformulasikan dalam bentuk pemujaan leluhur. Bentuk bakti kepada orang tua dan leluhur dilakukan dengan merawat abu leluhur di dalam rumah dan melakukan sembahyang untuk pemujaan 
Dea Letriana Cesaria: Religiositas Masyarakat Tionghoa dalam Cerpen di Majalah Star...

leluhur yang dipimpin oleh kepala keluarga (Lasiyo. et.al, 1995: 9).

Interaksi sosial dengan masyarakat dari berbagai etnis yang ada di Indonesia yang telah berlangsung lama menyebabkan pengaruh budaya dari etnis lain masuk ke dalam budaya Cina. Pengaruh budaya Melayu dan budaya Jawa tampak pada budaya Cina yang bersifat material (fisik) dan nonmaterial. Berkaitan dengan kegiatan religi, tradisi dan kepercayaan masyarakat Cina tidak mengalami pengaruh yang signifikan dari kepercayaan lain karena masyarakat Cina masih sangat kuat menjalankan aktivitas kepercayaan Tao dan Konfusius.

Berbicara mengenai kelahiran pers Tionghoa tidak bisa terlepas dari Khoe Woen Sioe dan Injo Beng Goat. Kedua tokoh ini merupakan perintis kehadiran majalah Tionghoa. Awalnya, mereka adalah pemimpin umum dan pemimpin redaksi harian Keng Po pada masa Jepang. Akan tetapi, koran ini dibredel atas tuduhan melawan pemerintah Jepang. Setelah keluar dari penjara, mereka mulai berusaha membangun kembali perusahaan pers dan lingkungan kerja yang sudah lama mereka tekuni sebelumnya. Mesin-mesin yang sudah dipreteli Jepang diperbaiki kembali. Modal usaha dikumpulkan lagi dari pemegang saham yang terdiri dari orang Tionghoa kaya tetapi kurang memperhatikan kegiatan pokok pers itu. Kedua tokoh pers Tionghoa itu memulai usaha persnya dengan menerbitkan majalah Star Weekly. Edisi pertama Star Weekly terbit pada 6 Januari 1946.

Pada awalnya Star Weekly diterbitkan sebagai edisi mingguan dari Star Magazine, sebuah majalah hiburan bulanan yang diproduksi oleh PT Keng Po. Star Magazine memuat cerita-cerita pendek, cerita bersambung, rubrik tanya jawab, horoskop, info-info ringan dan berbagi tips seputar kehidupan sehari-hari. Star Magazine dicetak dengan ukuran $27 \times 21 \mathrm{~cm}$ dan tebal halamannya mencapai ratusan lembar. Harga langganan untuk majalah Star Magazine edisi awal dibandrol f.2,25 per enam bulan dan terbit setiap tanggal 15 . Pemimpin redaksi pada saat itu ialah Tan Hian Lay (bekas redaktur Star Magazine) dibantu oleh Ie Tek Oen dan Khoe Woen Sioe. Dibandingkan dengan Star Magazine,
Star Weekly tampil dengan rubrik yang baru dan pembahasan yang baru. Isi Star Weekly yang dicetak di kertas koran itu antara lain pemandangan dalam negeri yang berisi ulasan dari berbagai peristiwa aktual dalam negeri, cerita pendek, serta kritik sosial yang berani dan pedas. Melihat isi dan bahasa yang digunakan, jelas sekali bahwa majalah ini merupakan bacaan yang ditujukan untuk golongan Tionghoa peranakan.

Setelah Star Weekly, terbitlah Majalah Pantjawarna. Majalah ini didirikan pada 1 Oktober 1948 di Jakarta dengan alamat Jalan Asemka 29-30 Jakarta Kota. Penerbit majalah ini adalah NV Percetakan Sin Po (NV Drukkerij Sin Po). Majalah "Bulanan Umum Bergambar" ini berukuran $31 \times 24$ $\mathrm{cm}$. Majalah ini banyak memuat karya sastra dalam rubriknya dengan motto "Memuat Sastra, Seni, Sejarah, Filsafat, Pengetahuan Umum". Pada mulanya majalah ini merupakan majalah bulanan umum bergambar.

\section{METODE PENELITIAN}

Metode yang digunakan dalam penelitian ini adalah metode kualitatif. Metode ini digunakan untuk menganalisis karya-karya cerpen yang terbit di majalah pada tahun 1950-an dengan beberapa pertimbangan.

Penelitian ini diawali dengan Pendahuluan. Dalam bagian ini dipaparkan latar belakang penelitian, rumusan permasalahan yang diangkat, tujuan dari penelitian, landasan teori yang dipakai, tinjauan pustaka, metode penelitian, ruang lingkup penelitian, serta sistematika penulisannya. Selanjutnya pemaparan mengenai konteks keadaan Indonesia tahun 1950-an. Tidak hanya itu, bagian ini juga menyajikan profil singkat dari majalah Star Weekly, Liberty, dan Pantjawarna pada periode 1950--1959. Tentunya, dalam pemaparan profil dari ketiga majalah tersebut dipaparkan pula penerbitan kesusastraannya. Langkah ketiga merupakan pemetaan kecenderungan tematik cerpen. Pada bagian ini pemaparan tema religiositas dilihat dari gesekan muncul antara masyarakat Tionghoa dan pribumi. Langkah keempat menyajikan analisis mengenai religiositas masyarakat Tionghoa yang ditampilkan dalam sejumlah cerpen yang diterbitkan oleh ketiga majalah. Dalam 
Dea Letriana Cesaria: Religiositas Masyarakat Tionghoa dalam Cerpen di Majalah Star...

penutup, memuat kesimpulan dari analisisanalisis yang telah dilakukan.

\section{HASIL DAN PEMBAHASAN}

\subsection{Konsep Satya dan Tepa Sarira dalam Agama Konghucu}

Konghucu adalah salah satu ajaran yang mempengaruhi pola pikir dan cara hidup sebagian umat manusia. Konghucu yang aslinya disebut - Ji Kauw (Hokkian) atau -Ju Chiao (Mandarin) berarti agama orang yang taat, lembut hati, terpercaya, dan beroleh bimbingan mengikuti jalan sucill. Karena itu, nilai kebajikan mendapat perhatian yang sangat penting. Salah satu dari nilai kebajikan adalah Chun Tzu yang berarti seorang gentleman, manusia unggul (insankami) yang telah memiliki kemanusiaan yang sempurna. Manusia yang berada pada derajat yang paling tinggi, yang memiliki kebijaksanaan dan budi luhur, yang di dalam dirinya terpantulkan sifat $-\mathrm{yi}$, jen, li, dan chih untuk menjadi manusia ideal. Nilai-nilai kebajikan tidak terlepas dari etika sebagai pendampingnya. Etika hubungan antara manusia dengan Tuhan, manusia dengan alam, dan manusia dengan manusia dapat mewujudkan keharmonisan dan perdamaian abadi.

\subsubsection{Hubungan Manusia dengan Tuhan}

Keyakinan pemeluk terhadap agama merupakan pusat dalam kehidupan beragama. Seperti halnya ungkapan yang terdapat di dalam Eka Prasetia Pancakarsa, bahwa agama dan kepercayaan terhadap Tuhan Yang Maha Esa adalah masalah yang menyangkut hubungan pribadi dengan Tuhan Yang Maha Esa yang dipercayai dan diyakininya. Tuhan dalam agama Konghucu disebut Thian. Dalam kitab-kitab agama Konghucu banyak bagian yang berbicara tentang Tuhan Yang Maha Esa, diantaranya: Kitab Shi Jing/ She Cing (kitab sajak/puisi) -kekuasaan dan bimbingan dari Thian (Tuhan Yang Maha Esa) sangat luas dan dalam hal ini di luar jangkauan suara, sentuhan, atau penciuman.

\subsubsection{Hubungan Manusia dengan Alam}

Pada dasarnya suku bangsa Cina awalnya hidup dalam dunia agraris (bertani).
Banyaknya masyarakat berhubungan dengan alam yang akhirnya mempengaruhi proses kejiwaan dan alam pikir mereka sebagai suatu keajaiban. Anggapan demikian menjadi sebab munculnya pemujaan-pemujaan terhadap yang gaib, dengan tujuan agar kekuatan gaib yang mereka yakini tidak menimbulkan kerusakan serta kejahatan pada kehidupan pertanian mereka. Pemikiran masyarakat petani yang primitif menjadikan hubungan yang erat dengan alam dan kekuatan kedewataan. Berbagai ritual dan pesta dirayakan sepanjang tahun yang bertujuan untuk meningkatkan hasil pertanian. Dalam ajaran agama Konghucu, alam semesta merupakan bukti kekuasaan Tuhan Yang Maha Esa. Menaruh kepercayaan serta memuja Shen yakni sejenis semangat atau arwah nenek moyang dan Kui yaitu tenaga alam seperti matahari, bulan, dan bintang. Umat agama Konghucu mempercayai Kui dan Shen dapat mempengaruhi dan mengatur alam ini. Kui dan Shen terbagi atas dua bagian yakni: pertama, yang tinggi, yaitu roh-roh yang tinggi termasuk roh-roh bintang; kedua, yang rendah, yaitu sungai, mata air, dan nyawa.

\subsubsection{Hubungan Manusia dengan Manusia}

Ajaran agama Konghucu dalam mengatur hubungan manusia dengan manusia merupakan unsur yang sangat penting dalam kehidupan sosial yakni lima kesopanan dalam masyarakat (Ngo Lun), di antaranya:

a. Hubungan seorang raja dengan menteri (atasan dengan bawahan)

b. Hubungan orang tua dengan anak

c. Hubungan suami dengan istri

d. Hubungan saudara dengan saudara

e. Hubungan teman dengan teman

Kelima hubungan di atas haruslah berjalan dengan baik. Apabila terlaksana akan mewujudkan keharmonisan antara bawahan dan atasan, antara anggota keluarga dalam suatu keluarga, antara keluarga dan masyarakat, antara anggota masyarakat dan negara, serta antara negara dan negara. Agar manusia dapat mencapai puncak kesejahteraan/ kedamaian/ kebahagiaan (Ci Sian), manusia harus berpedoman kepada agama karena 
Dea Letriana Cesaria: Religiositas Masyarakat Tionghoa dalam Cerpen di Majalah Star...

agama akan memberi penerangan, bimbingan, dan tuntunan.

Humanisme dalam agama Konghucu, merupakan ajaran satya dan tepasarira, yakni hubungan manusia dengan Tuhan, dan hubungan manusia dengan sesama manusia, termasuk juga hubungan manusia dengan alam semesta. Setiap umat harus menjaga keharmonisan tersebut agar terwujud perdamaian abadi dengan adanya kebijaksanaan, cinta kasih, dan keberanian. Dengan memahami makna kata humanisme di atas menunjukkan bahwa inti persoalan yang dibahas dalam humanisme adalah manusia itu sendiri, bagaimana membentuk manusia itu menjadi lebih manusiawi, serta pihak mana atau siapa yang bertanggungjawab pada proses pembentukannya.

Humanisme atau juga bisa disebut nilainilai kemanusiaan yang terdapat dalam agama Konghucu sangat erat kaitannya karena pedoman nilai-nilai dalam agama Konghucu selalu mengajarkan keharmonisan dan kerukunan dalam hidup di dunia. Arti kata humanisme menurut umat agama Konghucu adalah nilai-nilai kemanusiaan yang mengartikan ajaran satya dan tepa sarira. Nabi Kongzi mengartikan ajaran satya dan tepa sarira sebagai jalan suci Yang Satu yang Menembusi Semuanya, karena ajaran vertikal yang menjalinkan manusia kepada Tuhan dan horizontal yang menjalinkan manusia kepada sesama dan lingkungan hidupnya. Dalam hal ini, setiap umat wajib mengerti mana yang pokok dan mana yang ujung, serta mana yang wajib didahulukan dan mana yang wajib dikemudiankan.

\subsection{Humanisme dan Kearifan Budaya Jawa dalam Cerpen di Majalah Tionghoa}

Konsep satya dan tepa sarira juga kearifan budaya Jawa ditemukan dalam cerpencerpen di majalah Tionghoa. Hal ini berkaitan dengan latar dalam ketiga cerpen di Jawa Tengah. Ciri khas kebudayaan Jawa terletak pada kemampuan yang luar biasa meski kebudayaannya diterjang oleh budaya lain tetapi tetap bertahan dalam keasliannya (Suseno, 1988:1). Kebudayaan Jawa sebagai salah satu kebudayaan lokal di Nusantara mampu menjadi salah satu pilar kebudayaan nasional yang sampai sekarang belum jelas formulasinya. Kearifan budaya lokal yang tersebar di seluruh Nusantara secara nyata mampu menciptakan perilaku masyarakatnya lebih bermoral dan mempunyai kesantunan yang tinggi, sehingga rasa hormat terhadap sesama menjadi sebuah tingkat kepatuhan utama. Seperti terlihat dalam kutipan cerpen berikut.

Sook Sioe kuliah di Fakultas Ekonomi, Jakarta. Setiap bulan ia selalu berkirim surat ke rumahnya di Surabaya. Ada yang selalu menanti surat Sook Sioe tersebut yaitu Si Jem, pelayan yang mengasuh Sook Sioe sejak kecil, ia selalu berdoa untuk Sioe bahkan ia bersedih saat Sioe memutuskan untuk berangkat ke Jakarta. (Dua Putjuk Surat; Liberal No.689/14 Maret 1959)

Dalam interaksi sosial, masyarakat adat yang sudah berabad-abad mempunyai tatanan tradisi lokal mampu berperan dalam sebuah keselarasan kehidupan. Keselarasan ditampilkan dalam cerpen tersebut dan kesenjangan status sosial antara majikan dan pengasuh dihilangkan. Kerangka normatif dalam menentukan bentuk kongkret interaksi manusia Jawa adalah prinsip keselarasan hidup, baik mikrokosmos maupun dalam kapasitas sebagai bagian dari makrokosmos. Tandatanda ketegangan dalam interaksi sosial dalam masyarakat Jawa yang mulai tampak akan segera dihilangkan dengan prinsip kerukunan untuk mencapai sebuah keselarasan (Suseno, 1988).

Sikap batin dalam menjaga keselarasan interaksi sosial selalu dijaga dalam parameter yang bersifat ajeg, tidak ada gejolak, selalu mengedepankan kedamaian atau lebih dikenal dengan harmoni sosial. Hal itu dapat berjalan karena manusia Jawa merasa bahwa individu dengan segala kepentingannya merupakan bagian integral dari sebuah komunitas.

Terpeliharanya keseimbangan antara manusia dan alam pada titik normal akan menciptakan lingkungan yang selaras. Manusia akan secara sadar mengetahui tempatnya sehingga akan secara sadar pula dalam melakukan interaksi dengan sesama dan alam lingkungan. Sikap batin inilah yang mampu menciptakan harmonisasi kehidupan manusia dalam menjaga keutuhan alam. Manusia akan selalu merasa sebagai bagian dari rangkaian tata 
Dea Letriana Cesaria: Religiositas Masyarakat Tionghoa dalam Cerpen di Majalah Star...

kehidupan yang bersimbiosis, saling membutuhkan, sehingga dalam memperlakukan sesama atau lingkungan akan sangat berhati-hati dan santun.

Perilaku demikian sudah dikondisikan turun temurun sehingnga tidak merusak siklus keteraturan yang sudah berlaku, sehingga nyaris tidak terjadi konflik baik horizontal maupun vertikal. Kultur dari luar akan dengan mudah diterima bila dikemas dalam kultur Jawa yang asli sehingga terjadi sinkretisme yang justru sangat bisa diterima di masyarakat. Islam dalam syiarnya akan dengan mudah masuk dalam kehidupan Jawa ketika beberapa Wali menggunakan media budaya Jawa. Gamelan, wayang kulit dikemas menjadi syiar yang menarik, bukan secara frontal tetapi secara halus sesuai dengan nilai nilai budaya Jawa. Hal ini juga dilakukanuntuk bisa masuk ke kalangan Jawa santri. Demikian pula dengan Jawa abangan yang akan menolak secara tegas bila sistem tata nila tradisi mereka diberangus.

Kearifan adalah sebuah kemauan untuk menerima pranata yang ada (Amrih, 2008: 24). Dalam sistem pranata sosial masyarakat Jawa, kearifan sudah berlaku sejak jaman Hindu. Masyarakat Jawa mempunyai pandangan bahwa pusat kebudayaan Jawa adalah keraton, Kasunanan Surakarta dan Kesultanan Yogyakarta sebagai keturunan dinasti Mataram. Masyarakat Jawa yang sudah menyebar ke seluruh pelosok Nusantara baik melalui pola transmigrasi maupun kesadaran sendiri, masih mempunyai ikatan batin yang kuat terhadap budayanya, sehingga interaksi sosial tetap dalam sikap yang nJawani, walaupun tidak terekspresikan dalam budaya yang utuh. Namun paling tidak ada pernik-pernik budaya Jawa yang masih melekat erat. Seperti terlihat dalam kutipan cerpen berikut.

Liang Hwie yang berasal dari Magelang datang ke Jakarta untuk mencari kerja. Selama di Jakarta, ia menumpang di rumah temannya Hok Sing. Setiap hari, ia mencoba melamar pekerjaan dan ada panggilan kerja di P.F. Hwie. Saat sedang menunggu panggilan wawancara, ia berkenalan dengan Pak Suryo. Pak Suryo banyak bercerita tentang kehidupan pribadinya. Ia berharap mendapat pekerjaan karena keadaan ekonominya tidak menentu. Istrinya pun ikut bekerja untuk membantu menafkahi keluarga. Setelah wawancara, Hwie langsung pulang ke rumah dan bercerita kepada Hok Sing bahwa ia tidak diterima. Hok Sing kaget mendengar bahwa temannya yang memiliki ijazah SGA dan SMA tidak diterima. Sebaliknya, Pak Surjo yang hanya memiliki ijazah SGB diterima di sekolah tersebut. Liang Hwie menjelaskan lebih lanjut bahwa ia meminta kepada direktur sekolah tersebut untuk menerima Pak Surjo saja. Padahal yang harusnya diterima adalah dirinya. Tetapi, ia merasa Pak Surjo lebih membutuhkan pekerjaan tersebut.

(Tjari Pekerjaan; Star Weekly, 18 Des 1956)

Maka dalam komunitas Jawa tradisi, filosofinya akan bermuara pada sikap tepa slira, sehingga percikan-percikan perbedaan pendapat akan relatif mudah diredam. Kecenderungan relativisme Jawa dipahami sebagai sebuah penerimaan orang lain ketika memasuki komunitas kejawaan. Kelapangan teologis yang dimiliki masyarakat Jawa mampu memposisikan antar individu berjalan beriringan walau terdapat perbedaan konsep religius. Nilainilai tradisi Jawa dominan dalam persenyawaan antar religi ataupun etnis.

Cerpen ini mengisahkan tiga keluarga yang tinggal dalam satu rumah. Sebuah rumah yang disebut dengan rumah K.U.P. Tiga keluarga itu adalah keluarga tokoh aku, keluarga ntjek Pauw, dan keluarga Pak Ahmad. Sebelumnya di rumah K.U.P juga sudah tinggal 3 keluarga, tetapi tidak terjadi konflik yang hebat. Setelah salah satu keluarga tersebut ada yang pindah, yakni keluarga Weisz digantikan dengan keluarga Pak Ahmad konflik hebat terjadi dan mengakibatkan salah satu keluarga pindah, yakni keluarga Ntjek Pauw. Setelah beberapa kali mengalami konflik yang tidak berkesudahan, keluarga tokoh aku pun kemudian juga ikut pindah. (Rumah Tiga Keluarga; Pantjawarna No. 96/1 Agustus 1956)

\section{SIMPULAN}

Konsep Satya dan Tepa Sarira dalam ajaran Konghucu erat kaitannya dengan kebudayaan Jawa ditemukan dalam ketiga cerpen. Tepa salira merupakan salah satu filosofi kebudayaan Jawa yang menitikberatkan pada sikap toleransi menjaga perasaan orang lain bahkan berusaha membantu permasalahan yang 
Dea Letriana Cesaria: Religiositas Masyarakat Tionghoa dalam Cerpen di Majalah Star...

dihadapi orang lain agar terselesaikan. Sikap tersebut sangat penting dimiliki oleh masayarakat Indonesia yang memiliki keberagaman suku dan budaya sehingga rentan terjadi perselisihan, kesalahpahaman, sikap stereotip terhadap perbedaan. Hal tersebut dapat memecah persatuan Indonesia jika tidak diimbangi dengan sikap saling menghargai (toleransi). Secara mendalam, tepa salira merupakan kemampuan untuk merasakan (menjaga) perasaan (beban orang lain) sehingga tidak menyinggung perasaan atau dapat meringankan beban orang lain.

\section{DAFTAR PUSTAKA}

Abshar, Ulil. (2016). "Pengemis dan Salawat Badar: Hubungan antara Pengarang, Media, dan Karya" dalam Dialektika Vol.3, No.2. Hal. 201-215.

Hartono, Chris. (1974). Ke-Tionghoaan dan Kekristenan. Jakarta: Penerbit BPK Gunung Mulia.

Hidayat, Z.M. (1993). Masyarakat dan Kebudayaan Cina di Indonesia. Bandung: Penerbit Tarsito.

Kartodirdjo, Sartono, Marwati Djoened Poesponegoro, dan Nugroho Notosusanto. (1976). Sejarah Nasional Indonesia. Jakarta: Departemen Pendidikan dan Kebudayaan.

Koentjaraningrat. (1977). Lahirnya Konsesi Asimilasi. Jakarta: Penerbit Yayasan Tunas Bangsa.

Lasiyo, dkk. (1995). Konfusianisme di Indonesia. Pergulatan Mencari Jati Diri. Yogyakarta: Penerbit INTERFIDEI.

Magnis Suseno, Franz. (1988). Etika Jawa. Jakarta: PT Gramedia.

Pitoyo, Amrih. (2008). Ilmu Kearifan Jawa. Yogyakarta: Pinus Book Publisher.

Rosidi, Ajip. (1986). Ikhtisar Sejarah Sastra Indonesia. Bandung: Binacipta.
Ruth, T. McVey. (2011). "Kasus Tenggelamnya Sebuah Dasawarsa" dalam Antara Daerah dan Negara: Indonesia Tahun 1950-an Pembongkaran Narasi Besar Integrasi Bangsa. Jakarta: Yayasan Pustaka Obor Indonesia; KITLV-Jakarta.

Damono, Sapardi Djoko. (1978). Sosiologi Sastra Sebuah Pengantar Ringkas. Jakarta: Pusat Pembinaan dan Pengembangan Bahasa.

Sita van Bemmelen dan Ramco Raben. (2011). "Sejarah Daerah Tahun 1950an dan Dekonstruksi Narasi Besar Integrasi Nasional" dalam Antara Daerah dan Negara: Indonesia Tahun 1950-an Pembongkaran Narasi Besar Integrasi Bangsa. Jakarta: Yayasan Pustaka Obor Indonesia; KITLVJakarta.

Suryadinata, Leo. (1996). Sastra Peranakan Tionghoa Indonesia. Jakarta: Grasindo.

Tanggok, M. Ikhsan. (2000). Jalan Keselamatan Melalui Agama Konghucu. Jakarta: PT Gramedia Pustaka Utama.

(2005). Mengenal Lebih Dekat Agama Konghucu di Indonesia. Jakarta: Pelita Kebajikan.

Tu Wei-Ming. (2005). Etika Konfusianisme. Terjemahan Zubair. Jakarta: Penerbit Teraju PT Mizan Publika. 
Dea Letriana Cesaria: Religiositas Masyarakat Tionghoa dalam Cerpen di Majalah Star... 